\title{
Induction of microRNA-146a is involved in curcumin-mediated enhancement of temozolomide cytotoxicity against human glioblastoma
}

\author{
HAO WU ${ }^{1}$, QIANG LIU ${ }^{1}$, TAO CAI ${ }^{1}$, YU-DAN CHEN ${ }^{2}$ and ZHI-FEI WANG ${ }^{1}$ \\ ${ }^{1}$ Department of Neurosurgery; ${ }^{2}$ Hemodialysis Room, Xiangya 3rd Hospital, Changsha, Hunan 410013, P.R. China
}

Received August 8, 2014; Accepted June 29, 2015

DOI: $10.3892 / \mathrm{mmr} .2015 .4087$

\begin{abstract}
MicroRNA (miR)-146a is a negative regulator of nuclear factor- $\kappa \mathrm{B}(\mathrm{NF}-\kappa \mathrm{B})$ signaling that affects tumor growth and survival. The present study was undertaken to determine whether the cytotoxicity of curcumin (diferuloylmethane), a natural polyphenolic compound isolated from turmeric (Curcuma longa Linn), in glioblastoma cells is mediated through upregulation of miR-146a. Human U-87 MG glioblastoma cells were treated with curcumin and temozolomide (TMZ) alone or in combination, and cell proliferation and apoptosis were assessed. The involvement of miR-146a and $\mathrm{NF}-\kappa \mathrm{B}$ signaling in curcumin-mediated chemosensitization was explored. Curcumin exposure led to upregulation of miR-146a in U-87 MG cells. Combined curcumin and TMZ treatment significantly $(\mathrm{P}<0.05)$ inhibited $\mathrm{U}-87 \mathrm{MG}$ cell proliferation and induced apoptotic death, compared with each alone. Notably, curcumin-mediated enhancement of TMZ-induced apoptosis was blocked by depletion of miR-146a. By contrast, miR-146a overexpression enhanced apoptosis and suppressed $\mathrm{NF}-\kappa \mathrm{B}$ activation in TMZ-treated cells. Additionally, pharmacological inhibition of NF- $\kappa \mathrm{B}$ signaling significantly increased TMZ-induced apoptosis. To the best of our knowledge, the present study provides the first evidence that upregulation of miR-146a and inactivation of NF- $\mathrm{B}$ signaling mediates the sensitization of human glioblastoma cells to TMZ-induced apoptosis by curcumin.
\end{abstract}

\section{Introduction}

Glioblastoma is a highly aggressive brain tumor that is commonly resistant to existing chemotherapeutic agents (1). Temozolomide (TMZ) is a DNA alkylating agent and has been shown to prolong the survival of patients with glioblastoma, when used in combination with surgery

Correspondence to: Dr Zhi-Fei Wang, Department of Neurosurgery, Xiangya 3rd Hospital, 138 Tongzipo Road, Changsha, Hunan 410013, P.R. China

E-mail: zfei_wang@163.com

Key words: apoptosis, chemosensitization, glioblastoma, microRNA, phytochemical, signaling pathway and radiation therapy $(2,3)$. However, due to the primary and acquired drug resistance, the survival benefit of TMZ chemotherapy remains limited. Elevated expression of $\mathrm{O}^{6}$-methylguanine-DNA-methyltransferase (MGMT), a DNA repair enzyme that removes TMZ-generated methyl groups at the $\mathrm{O}^{6}$ position of guanine, represents a major mechanism of TMZ resistance (4). The transcription factor nuclear factor- $\kappa \mathrm{B}$ $(\mathrm{NF}-\kappa \mathrm{B})$, which is constitutively activated in human glioblastoma, is important in the regulation of MGMT expression (5). The majority of $N F-\kappa B$ exists as a heterodimer of p65/p50 proteins that are sequestered in the cytoplasm by inhibitor of $\kappa \mathrm{B}(\mathrm{I} \kappa \mathrm{B})$ proteins. Phosphorylation and degradation of I $\mathrm{B} \alpha$ results in the liberation of the $\mathrm{p} 65 / \mathrm{p} 50$ heterodimer for its translocation to the nucleus where it transactivates target genes (6). Evidence indicates that phosphorylation of p65 at serine 536 is involved in the nuclear import and transcriptional activity of p65 (7). Inhibition of $\mathrm{NF}-\kappa \mathrm{B}$ signaling has been found to reverse TMZ resistance by downregulation of MGMT in T98 G glioblastoma cells (8). Therefore, the combination with $\mathrm{NF}-\kappa \mathrm{B}$ inhibitors may provide a promising strategy to improve the efficacy of TMZ chemotherapy against glioblastoma.

Curcumin (diferuloylmethane), a hydrophobic polyphenol molecule extracted from turmeric (Curcuma longa Linn), has a wide range of pharmacological activities, including anti-inflammatory, antioxidant and anticancer properties (9). Curcumin exerts a suppressive effect on NF- $\kappa \mathrm{B}$ activity in various biological contexts $(10,11)$. For instance, curcumin has been found to enhance the chemosensitization of colorectal cancer cells to conventional chemotherapeutic agents, such as 5-fluorouracil through inhibition of NF- $\mathrm{B}$ and Src protein kinase signaling pathways (10). In malignant gliomas, curcumin also exhibits chemosensitizing activity through suppression of AP-1 and NF- $\kappa$ B signaling pathways (12). It is thus suggested that such activity of suppressing $N F-\kappa B$ signaling may be exploited to overcome TMZ resistance. Indeed, curcumin was reported to potentiate TMZ cytotoxicity against glioblastoma cells (13). However, the mechanisms underlying curcumin-mediated chemosensitization are not fully understood.

MicroRNAs (miRNAs) are a class of endogenous non-coding regulatory RNAs of $\sim 22$ nucleotides. They are important in tumorigenesis, acting as oncogenes or tumor suppressor genes (14). A single miRNA can simultaneously regulate a large number of target genes and thus affect 
various biological processes, such as cell proliferation, differentiation, migration, invasion and apoptosis $(14,15)$. miR-146a is known to be a negative regulator of the NF- $\kappa$ B signaling pathway $(16,17)$. Celastrol, a plant triterpene, has been shown to induce the apoptosis of gastric cancer cells via miR-146a-mediated inhibition of NF- $\mathrm{KB}$ activity (16). Notably, diflourinated-curcumin (CDF) is capable of switching on suppressor miRNAs including miR-146a in pancreatic cancer, consequently leading to reduced tumor growth and aggressiveness (18). These findings suggest that the induction of miR-146a and suppression of NF- $\mathrm{NB}$ signaling could partially account for the enhanced curcumin-induced TMZ cytotoxicity in glioblastoma.

Therefore, in the present study, the cytotoxic effects of curcumin and TMZ, alone or in combination in human glioblastoma cells were investigated and the involvement of miR-146a and $\mathrm{NF}-\kappa \mathrm{B}$ signaling were explored in curcumin-mediated chemosensitization.

\section{Materials and methods}

Cell culture and drug treatment. U-87 MG human glioblastoma cells were obtained from the Shanghai Cell Bank of Chinese Academy of Sciences (Shanghai, China) and maintained in high glucose Dulbecco's modified Eagle's medium supplemented with $10 \%$ fetal bovine serum (), $100 \mathrm{U} / \mathrm{ml}$ penicillin, and $100 \mu \mathrm{g} / \mathrm{ml}$ streptomycin (all from Invitrogen Life Technologies, Carlsbad, CA, USA). The cells were seeded at a density of $2 \times 10^{5}$ cells/well onto 12 -well plates. After incubation overnight to allow cell attachment, curcumin (Sigma-Aldrich, St. Louis, MO, USA) and TMZ (Suzhou Bichal Biological Technology, Suzhou, China) at different concentrations were added alone or in combination to the cell cultures. The control cells were treated with $0.5 \%$ dimethyl sulfoxide (DMSO; Sigma-Aldrich). After incubation for $72 \mathrm{~h}$, cells were harvested for assessment of cell proliferation and apoptosis. If not stated otherwise, $20 \mu \mathrm{M}$ curcumin and $100 \mu \mathrm{M}$ TMZ were used. For inhibition of NF- $\mathrm{NB}$ signaling, cells were pretreated with $100 \mu \mathrm{M}$ pyrrolidine dithiocarbamate (PDTC; Sigma-Aldrich) (19) for $1 \mathrm{~h}$ prior to TMZ treatment.

miRNA oligonucleotides and transfection. Locked nucleic acid (LNA)-based anti-human miR-146a and universal LNA-based negative control were purchased from Exiqon (Vedbaek, Denmark), and human pre-miR-146a and pre-miR negative control oligonucleotides were purchased from Ambion (Austin, TX, USA). For depletion of endogenous miR-146a, U-87 MG cells were transiently transfected with LNA-anti-miR-146a or LNA inhibitor control, using Lipofectamine ${ }^{\mathrm{TM}} 2000$ (Invitrogen Life Technologies) according to the manufacturer's instructions. For overexpression of miR-146a, pre-miR-146a or negative control oligonucleotides were transfected into U-87 MG cells using Lipofectamine 2000. The final concentration of each oligonucleotide was $50 \mathrm{nM}$. At $24 \mathrm{~h}$ post transfection, the cells were exposed to curcumin and/or TMZ.

Reverse transcription-quantitative polymerase chain reaction (RT-qPCR). Total RNA was isolated from cells using the mirVana miRNA Isolation kit (Ambion ${ }^{\circledR}$, Austin, TX, USA). The level of mature miR-146a was determined using
Taqman miRNA assays (Applied Biosystems, Foster City, CA, USA). Briefly, cDNA was synthesized with a miRNA-specific stem-loop primer, and quantitative PCR was performed using the 7900HT Fast Real-Time PCR system (Applied Biosystems). Cycling conditions were as follows: $95^{\circ} \mathrm{C}$ for $10 \mathrm{~min}$, followed by 40 cycles at $95^{\circ} \mathrm{C}$ for $15 \mathrm{sec}$, and $60^{\circ} \mathrm{C}$ for $1 \mathrm{~min}$. The primers for miR-146a were as follows: Forward: 5'-GCCCTGAGAACTGAATTCCATG-3' and reverse: 5'-GTGCAGGGTCCGAGGTAACCCA-3'. The relative amount miR-146a normalized to the U6 small nuclear RNA level was calculated using the comparative cycle threshold $(\Delta \Delta \mathrm{Ct})$ method (20). Each assay was conducted in triplicate.

Cell proliferation assay. U-87 MG cells were seeded in triplicate in 96-well microplates at a density of $6 \times 10^{3}$ cells/well. After drug treatment, cells were subjected to cell viability analysis using the 3-(4,5-dimethylthiazol-2-yl)-2,5-diphenyltetrazoliumbromide (MTT) method. MTT solution $(5 \mathrm{mg} / \mathrm{ml}$; Sigma Aldrich) was added to the cell cultures and incubated at $37^{\circ} \mathrm{C}$ for $4 \mathrm{~h}$. Following the removal of the MTT solution, DMSO solution was added to dissolve formazan crystals. The absorbance was measured at a wavelength of $570 \mathrm{~nm}$ using a Bio-Rad 96-well plate reader (model 550, Bio-Rad, Hercules, CA, USA). The experiments were repeated three times. Results were expressed as the percentage relative to DMSO-treated control cells (defined as 100\%).

Apoptosis analysis by flow cytometry. Following drug treatment, cells were harvested by treatment with trypsin (Invitrogen Life Technologies), washed three times, and resuspended in phosphate-buffered saline (PBS). Cell apoptosis was determined using the Annexin V Apoptosis kit (Becton Dickinson, San Diego, CA, USA). A single cell suspension $\left(100 \mu \mathrm{l} ; 2 \times 10^{6}\right.$ cells $\left./ \mathrm{ml}\right)$ was stained with fluorescein isothiocyanate-conjugated Annexin $\mathrm{V}$ and propidium iodide (PI) solution $(20 \mu \mathrm{g} / \mathrm{ml})$ and incubated for $15 \mathrm{~min}$ in the dark. Apoptotic cells (Annexin V-positive) were analyzed by flow cytometry (A BD LSR II Flow Cytometer; Becton Dickinson). Each assay was performed in triplicate and repeated three times.

Western blot analysis. Whole cell lysates were prepared in lysis buffer [10 mM Tris/HCl, pH 6.8; $10 \%$ glycerol, $2 \%$ sodium dodecyl sulfate (SDS), $1 \%$ Triton X-100 and 1\% Nonidert P40] containing $1 \mathrm{mM}$ phenylmethanesulfonyl fluoride and complete protease inhibitors (Roche, Mannheim Germany). Samples of the lysates containing $\sim 50 \mu$ g protein were separated by SDS-polyacrylamide gel electrophoresis and transferred to polyvinylidene fluoride membranes (Millipore, Bedford, MA, USA). Subsequent to incubation for $1 \mathrm{~h}$ in blocking solution containing $5 \%$ fat-free milk, membranes were incubated at $4{ }^{\circ} \mathrm{C}$ overnight with primary antibodies. Primary antibodies used were as follows: Rabbit anti-human I $\mathrm{B} \alpha$ polyclonal antibody

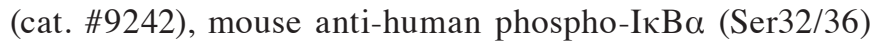
monoclonal antibody (cat. no. 9246), rabbit anti-human NF- $\kappa$ B p65 polyclonal antibody (cat. no. 8242), rabbit antihuman phospho-NF-кB p65 (Ser536) polyclonal antibody (cat. \#3031), and mouse anti-human $\beta$-actin monoclonal antibody (cat. no. 3700). These antibodies were purchased from Cell Signaling Technology Inc. (Beverly, MA, USA). All antibodies 
A

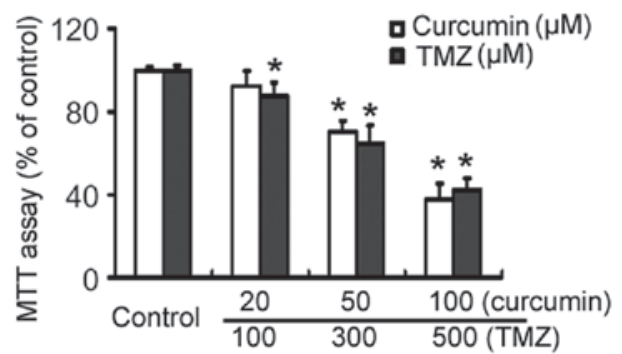

C

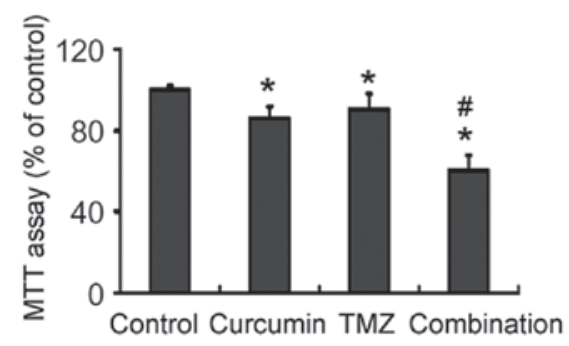

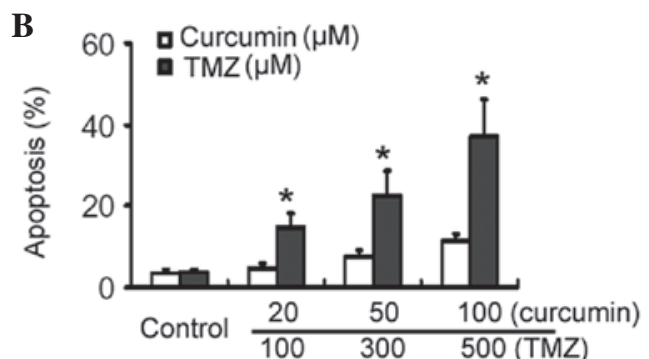

D

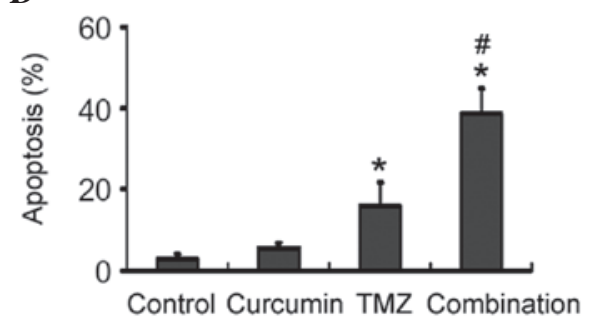

Figure 1. Effect of curcumin and TMZ on U-87 MG cell proliferation and apoptosis. U-87 MG cells were exposed to curcumin and TMZ alone at the indicated concentrations for $72 \mathrm{~h}$ and were then harvested for analysis of proliferation and apoptosis. (A) Cell proliferation measured by an MTT. Results were expressed as a percentage of dimethyl sulfoxide-treated control cells (assigned 100\%). (B) Apoptosis determined by the Annexin-V/propidium iodide staining. Columns, mean percentage of three independent experiments; bars, standard deviation. ${ }^{*} \mathrm{P}<0.05$ vs. the control. Cells were treated with curcumin $(20 \mu \mathrm{M})$ and $\mathrm{TMZ}$ $(100 \mu \mathrm{M})$ alone or in combination for $72 \mathrm{~h}$ and $(\mathrm{C})$ cell proliferation and (D) apoptosis were assessed as described in $\mathrm{A}$ and $\mathrm{B}$, respectively. "P<0.05 vs. the control; ${ }^{~} \mathrm{P}<0.05$ vs. curcumin- or TMZ-treated cells. TMZ, temozolomide; MTT, 3-(4,5-dimethylthiazol-2-yl)-2,5-diphenyltetrazoliumbromide assay.

except $\beta$-actin (1:3,000 dilution) were diluted 1:500 before use. Membranes were washed and incubated with appropriate horseradish peroxidase-conjugated secondary antibodies (sc-2030 and sc-2005; Santa Cruz Biotechnology, Santa Cruz, CA, USA) for $1 \mathrm{~h}$. Immunoreactive bands were visualized with an enhanced chemiluminescent detection system (Amersham Biosciences, Piscataway, NJ, USA) according to the manufacturer's instructions. Densitometry was performed using Quantity One software (version 4.6.8; Bio-Rad).

$N F-\kappa B$ luciferase activity assay. The reporter plasmid pNF- $\kappa \mathrm{B}-$ Luc containing four copies of NF- $\kappa \mathrm{B}$ enhancer elements and a firefly luciferase gene were purchased from Beyotime Institute of Biotechnology (Haimen, China) and the pRL-TK Renilla luciferase control reporter vector from Promega Corporation (Madison, WI, USA). U-87 MG cells were seeded at a density of $2 \times 10^{5}$ cells/well onto 12 -well plates and transiently transfected with pNF-кB-luc $(0.5 \mu \mathrm{g})$ and pRL-TK $(0.02 \mu \mathrm{g})$ together with pre-miR-146a or control oligonucleotides. After transfection $(24 \mathrm{~h})$, the cells were treated with $100 \mu \mathrm{M}$ TMZ for $72 \mathrm{~h}$ and harvested. The firefly and Renilla luciferase activities were measured in the cellular lysates using the dual-luciferase reporter assay kit (Promega Corporation), according to the manufacturer's instructions. Firefly luciferase activity was normalized to the Renilla luciferase activity, which served as an internal control for transfection efficiency.

Statistical analysis. Data are presented as the mean \pm standard deviation. The difference among the means of multiple groups was analyzed by one-way analysis of variance followed by Tukey's test. All statistical calculations were performed using SPSS.11 software (SPSS Inc., Chicago, IL, USA). P $<0.05$ was considered to indicate a statistically significant difference.

\section{Results}

Combination of curcumin and TMZ enhances the cytotoxic effects on U-87 MG cells. The MTT assay revealed that exposure to curcumin and TMZ alone for $72 \mathrm{~h}$ resulted in a significant dose-dependent inhibition of U-87 MG cell viability, as compared with control cells (Fig. 1A). Flow cytometric analysis revealed that treatment with TMZ caused significant apoptosis of U-87 MG cells (Fig. 1B). Curcumin at $100 \mu \mathrm{M}$ also promoted apoptosis in U-87 MG cells. TMZ induced apoptosis in a concentration-dependent manner. When treated with $500 \mu \mathrm{M}$ TMZ for $72 \mathrm{~h}$, the cells exhibited an $\sim 10$-fold higher apoptosis rate than control cells (37.2 $\pm 8.9 \%$ vs. $3.8 \pm 0.6 \%$, respectively; $\mathrm{P}<0.05$ ). Notably, the combination of suboptimal doses of curcumin $(20 \mu \mathrm{M})$ and TMZ $(100 \mu \mathrm{M})$ showed significantly $(\mathrm{P}<0.05)$ greater growth-suppressive effects against U-87 MG cells than each alone (Fig. 1C). Moreover, TMZ-induced apoptosis was significantly $(\mathrm{P}<0.05)$ enhanced by its combination with $20 \mu \mathrm{M}$ curcumin (Fig. 1D).

Curcumin induces miR-146a expression in U-87 MG cells. RT-qPCR analysis showed that treatment with curcumin for $48 \mathrm{~h}$ caused a significant $(\mathrm{P}<0.05)$ elevation in the miR-146a level in U-87 MG cells, compared with control cells (Fig. 2). Moreover, such elevation occurred in a dose-dependent manner, with $\sim 4-$ and 6-fold increase at 20 and $100 \mu \mathrm{M}$ curcumin, respectively (Fig. 2). However, the miR-146a level remained unchanged in TMZ-treated U-87 MG cells (data not shown).

miR-146a mediates the increase in TMZ-induced apoptosis by curcumin. Having identified the upregulation of miR-146a by curcumin, the role of miR-146a in curcumin-mediated 


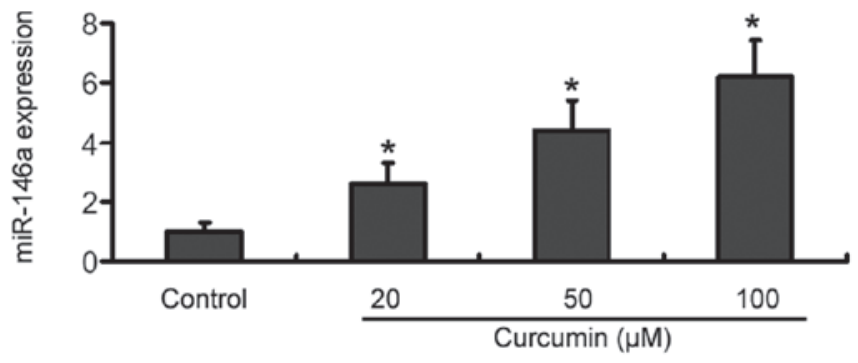

Figure 2. Curcumin induces the expression of miR-146a in U-87 MG cells. Bar graphs represent the mean \pm standard deviation of three independent experiments. Results are expressed as fold change relative to vehicle-treated control cells (assigned as 1 ). ${ }^{*} \mathrm{P}<0.05$ vs. control cells. miR, microRNA.

A

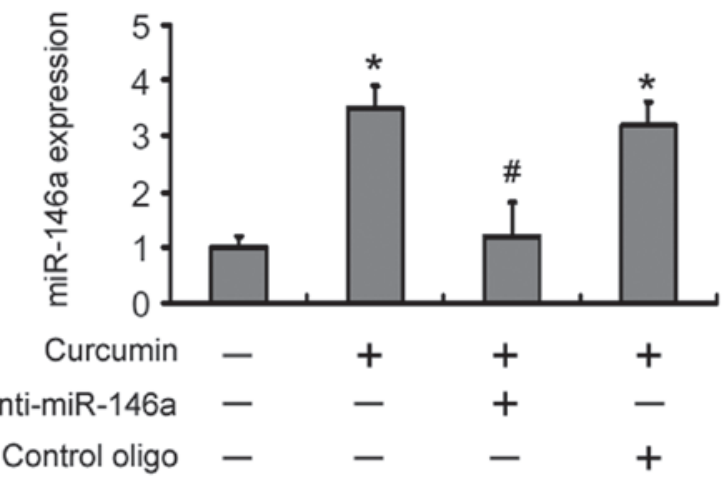

B

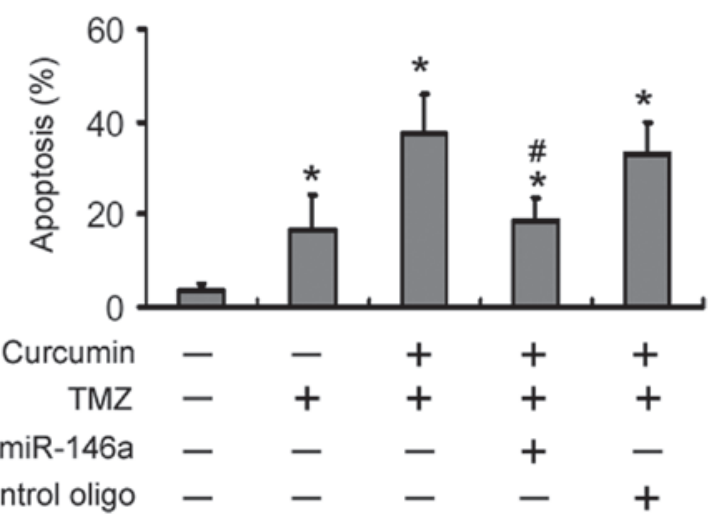

Figure 3. Depletion of miR-146a antagonizes the enhancement of TMZ-induced apoptosis by curcumin. (A) Measurement of miR-146a expression in U-87 MG cells treated with curcumin with or without pre-transfection with anti-miR-146a or control olionucleotides (oligo). Bar graphs represent the mean \pm SD of three independent experiments. Results are expressed as fold change relative to untreated control cells (assigned as 1 ). ${ }^{*} \mathrm{P}<0.05$ vs. control cells; ${ }^{~} \mathrm{P}<0.05$ vs. curcumin alone. (B) Apoptosis detection in U-87 MG cells with indicated treatments. Columns, mean percentage of three independent experiments; bars, SD. ${ }^{*} \mathrm{P}<0.05$ vs. the control; ${ }^{~} \mathrm{P}<0.05$ vs. the combination of curcumin and TMZ. TMZ, temozolomide; miR, microRNA; $\mathrm{SD}$, standard deviation.

chemosensitization was next determined. Pre-transfection with LNA-anti-miR-146a almost completely inhibited the upregulation of miR-146a by curcumin $(\mathrm{P}<0.05$ vs. transfection with control oligonucleotides; Fig. 3A). Notably, depletion of miR-146a reduced the curcumin-mediated increase in of TMZ-induced apoptosis by $~ 50 \%$ (Fig. 3B). However, apoptosis was not observed in U-87 MG cells transfected with either LNA-anti-miR-146a or control oligonucleotide (data not shown).
A

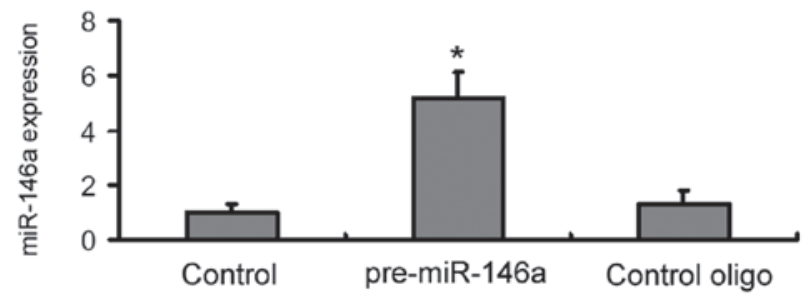

B

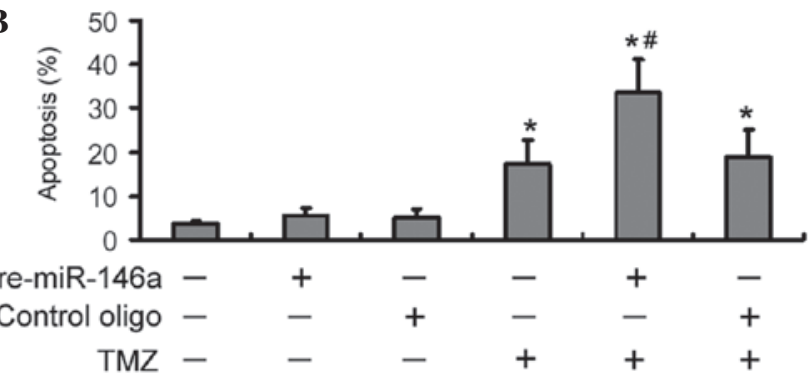

Figure 4. Enforced expression of miR-146a sensitizes U-87 MG cells to TMZ-induced apoptosis. (A) Measurement of miR-146a expression in U-87 MG cells transfected with pre-miR-146a or control oligonucleotides (oligo). Bar graphs represent the mean \pm SD of three independent experiments. Results were expressed as fold change relative to non-transfected control cells (assigned as 1). ${ }^{*} \mathrm{P}<0.05$ vs. control cells. (B) Apoptosis detection in U-87 MG cells with indicated treatments. Columns, mean percentage of three independent experiments; bars, SD. " $\mathrm{P}<0.05$ vs. the control; ${ }^{\text {"}} \mathrm{P}<0.05$ vs. TMZ treatment alone. miR, microRNA; TMZ, temozolomide; SD, standard deviation.

Forced expression of miR-146a sensitizes $U-87$ MG cells to TMZ-induced apoptosis. Next, it was analyzed whether overexpression of miR-146a conferred chemosensitization to TMZ in U-87 MG cells. RT-qPCR analysis showed that the miR-146a level was significantly increased in pre-miR-146a-transfected U-87 MG cells than in control oligonucleotide-transfected cells (Fig. 4A). Apoptosis analysis revealed that overexpression of miR-146a significantly $(\mathrm{P}<0.05)$ enhanced TMZ-induced apoptosis by $\sim 2$-fold, compared with the delivery of control oligonucleotides (Fig. 4B). However, transfection of miR-146a alone did not significantly alter cell apoptosis.

miR-146a suppresses $N F-\kappa B$ signaling in $U-87 M G$ cells exposed to $T M Z$. Finally, it was examined whether the chemosensitive effects of miR-146a were associated with suppression of NF- $\kappa$ B signaling. As shown in Fig. 5A, miR-146a overexpression markedly inhibited the phosphorylation of $\mathrm{I} \kappa \mathrm{B} \alpha$ and p65 in TMZ-treated U-87 MG cells and increased the total level of $\mathrm{I} \kappa \mathrm{B} \alpha$. However, the total level of NF- $\kappa \mathrm{B}$ p 65 remained unchanged. The luciferase reporter assay demonstrated that the delivery of pre-miR-146a led to a significant $(\mathrm{P}<0.05)$ decline in the $\mathrm{NF}-\kappa \mathrm{B}$ transcriptional activity in control and TMZ-treated cells (Fig. 5B). Notably, pharmacological inhibition of NF- $\mathrm{B}$ signaling significantly increased TMZ-induced apoptosis in U-87 MG cells compared with DMSO-treated cells (Fig. 5C), which resembles the results obtained with overexpression of miR-146a. However, PDTC alone failed to induce significant apoptosis in U-87 MG cells.

\section{Discussion}

Curcumin and its synthetic analogues have shown anticancer properties in various types of cancer cell (21). By contrast, 


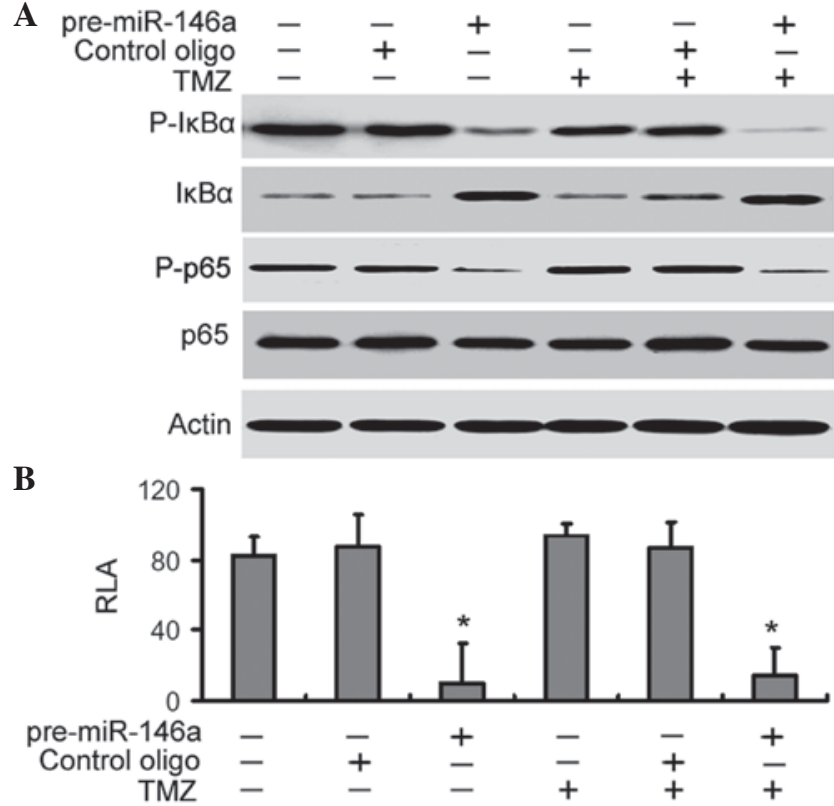

C

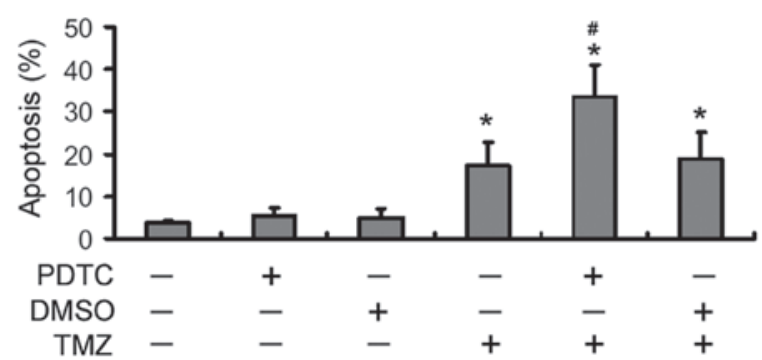

Figure 5. miR-146a suppresses NF-кB signaling in U-87 MG cells exposed to TMZ. (A) Cells were transfected with pre-miR-146a or control oligonucleotides (oligo) and treated with or without TMZ. Western blot analysis of the protein levels of total and phosphorylated IкB $\alpha$ and $\mathrm{p} 65$. Representative blots of three independent experiments with similar results are shown.

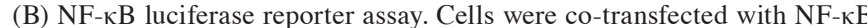
luciferase reporter together with pre-miR-146a or control oligonucleotides and RLA was measured as described in the Materials and methods. Bar graphs show the mean $\pm \mathrm{SD}$ of three independent experiments. ${ }^{*} \mathrm{P}<0.05$ vs. the control. (C) Effects of pharmacological inhibition of NF- $\mathrm{kB}$ signaling on TMZ-induced apoptosis. Cells were pre-treated with PDTC or DMSO prior to exposure to TMZ and cell apoptosis was examined. Columns, mean percentage of three independent experiments; bars, $\mathrm{SD}$. ${ }^{*} \mathrm{P}<0.05$ vs. the control; ${ }^{\text {"}} \mathrm{P}<0.05$ vs. TMZ treatment alone. miR, microRNA; TMZ, temozolomide $\mathrm{I} \kappa \mathrm{B} \alpha$, inhibitor $\kappa \mathrm{B} \alpha$; NF- $\kappa \mathrm{B}$, nuclear factor- $\kappa \mathrm{B}$; RLA, relative luciferase actvity; SD, standard deviation; PDTC, pyrrolidine dithiocarbamate; DMSO, dimethyl sulfoxide.

curcumin has been shown to protect normal organs, such as the liver, kidney, oral mucosa and heart from chemotherapy and radiotherapy-induced toxicity (22). Given its safety and tolerability (23), curcumin can be used alone or in combination with other chemotherapeutic agents in the treatment of neoplastic diseases. Preclinical studies have demonstrated that curcumin is capable of suppressing tumor growth in glioblastoma $(24,25)$. Consistently, the present data indicated a dose-dependent cytotoxic effect of curcumin on U-87 MG cells. Moreover, when suboptimal doses of curcumin and TMZ were combined, a significant increase in the suppression of cell viability was observed. These results confirm the potentiation of cytotoxicity by combination of curcumin and $\mathrm{TMZ}$ in glioblastoma cells. It is noteworthy that curcumin at
20-100 $\mu \mathrm{M}$ did not induce significant apoptosis in U-87 MG cells as determined by Annexin-V/PI staining. Aoki et al (25) reported that curcumin causes $\mathrm{G} 2 / \mathrm{M}$ arrest and nonapoptotic autophagic cell death in malignant glioma cells, which may provide an explanation for the growth-suppressive effects of curcumin. Notably, curcumin showed the capacity to promote TMZ-induced apoptosis, which partially explains the enhanced cytotoxicity by combination of curcumin and TMZ.

A number of miRNAs have been identified to modulate radio- and chemoresistance of gliomas (26). For instance, miR-21 is implicated in the acquisition of TMZ resistance in glioblastoma cells and its inhibition leads to a significant increase in TMZ-induced apoptosis (27). miR-195, miR-455-3p, and miR-10a* are also implicated in acquired TMZ resistance in glioblastoma cells (28). In this study, it was demonstrated that miR-146a was upregulated by curcumin but not TMZ in U-87 MG cells. The upregulation of miR-146a by the CDF curcumin analogue has been previously described in pancreatic cancer (18). It has been documented that ectopic expression of miR-146a inhibits the glioma development of a human glioblastoma cell line in an orthotopic xenograft model (29). However, manipulating miR-146a expression alone had no significant effect on U-87 MG cell apoptosis, which suggests that the inhibitory function of miR-146a on gliomas is largely attributable to apoptosis-independent mechanisms. Our data further revealed that miR-146a mediated the chemosensitizing activity of curcumin, as evidenced by the finding that its depletion significantly antagonized TMZ-induced apoptosis even in the presence of curcumin. Moreover, miR-146a overexpression significantly enhanced TMZ-induced apoptosis in U-87 MG cells. These results indicate that miR-146a as a responsive miRNA to curcumin treatment is critical in the modulation of the susceptibility of glioblastoma cells to TMZ. The potential implication of miR-146a in acquired chemoresistance is also documented in breast cancer cells (30). The present data expand the list of candidate miRNAs as therapeutic targets for increasing the chemosensitivity of glioblastoma cells.

The NF- $\kappa \mathrm{B}$ pathway is implicated in the progression of glioblastoma and targeting NF- $\mathrm{B}$ may thus provide therapeutic benefits in this disease (31). It has previously been documented that treatment with dehydroxymethylepoxyquinomicin (DHMEQ), a unique small molecule inhibitor of $\mathrm{NF}-\kappa \mathrm{B}$, induces G2/M arrest and apoptosis in glioblastoma cells (32). Targeting NF- $\kappa \mathrm{B}$ via DHMEQ is capable of improving the sensitivity of human glioblastoma cells to TMZ (33). miR-146a has been found to act as a suppressor of NF- $\kappa \mathrm{B}$ signaling in multiple biological contexts $(16,17)$. The present data indicated that enforced expression of miR-146a significantly inhibited the transcriptional activity of NF- $\kappa \mathrm{B}$ in TMZ-treated U-87 MG cells, as determined by a luciferase reporter assay. Moreover, pharmacological inhibition of $\mathrm{NF}-\kappa \mathrm{B}$ signaling sensitized U-87 MG cells to TMZ-induced apoptosis, which is similar to the findings with overexpression of miR-146a. These results collectively point towards a critical role of the miR-146a/NF- $\kappa$ B axis in the regulation of TMZ cytotoxicity. Several targets of miR-146a, such as caspase recruitment domain-containing protein 10 (CARD10), COP9 signalosome complex subunit 8 (COPS8 (17) and TNF receptor-associated factor 6 (34), have been identified. Repressing CARD10 and COPS8 expression is predominantly responsible for the miR-146a-induced 
suppression of NF- $\mathrm{NB}$ activation in gastric cancer (17), while in the setting of natural killer/T cell lymphoma, targeting TRAF6 is linked to the downregulation of NF- $\kappa \mathrm{B}$ activity by miR-146a (34). However, the direct target mediating the inhibitory effects of miR-146a in glioblastoma remains to be identified.

In conclusion, the data demonstrated that curcumin sensitizes glioblastoma cells to TMZ-induced apoptosis, which is, at least partially mediated through regulation of the $\mathrm{miR}-146 \mathrm{a} / \mathrm{NF}-\kappa \mathrm{B}$ axis. These findings warrant further exploration of the potential clinical utility of curcumin for improving the efficacy of TMZ chemotherapy in glioblastoma. The therapeutic potential of manipulating the miR-146a/NF- $\kappa \mathrm{B}$ axis in glioblastoma also requires further investigation.

\section{References}

1. Lwin Z, MacFadden D, Al-Zahrani A, Atenafu E, Miller BA, Sahgal A, Menard C, Laperriere N and Mason WP: Glioblastoma management in the temozolomide era: have we improved outcome? J Neurooncol 115: 303-310, 2013.

2. Julka PK, Sharma DN, Mallick S, Gandhi AK, Joshi N and Rath GK: Postoperative treatment of glioblastoma multiforme with radiation therapy plus concomitant and adjuvant temozolomide: A mono-institutional experience of 215 patients. J Cancer Res Ther 9: 381-386, 2013.

3. Alnaami IM, Al-Nuaimi SK, Senthilselvan A, Murtha AD, Walling S, Mehta V and Gourishankar S: Effectiveness of adjuvant temozolomide treatment in patients with glioblastoma. Neurosciences (Riyadh) 18: 349-355, 2013.

4. Bocangel DB, Finkelstein S, Schold SC, Bhakat KK, Mitra S and Kokkinakis DM: Multifaceted resistance of gliomas to temozolomide. Clin Cancer Res 8: 2725-2734, 2002.

5. Lavon I, Fuchs D, Zrihan D, Efroni G, Zelikovitch B, Fellig Y and Siegal T: Novel mechanism whereby nuclear factor kappaB mediates DNA damage repair through regulation of $\mathrm{O}$ (6)-methylguanine-DNA-methyltransferase. Cancer Res 67: 8952-8959, 2007.

6. Baldwin AS Jr: The NF-kappaB and I kappaB proteins: new discoveries and insights. Annu Rev Immunol 14: 649-683, 1996.

7. Mattioli I, Sebald A, Bucher C, et al: Transient and selective NF-kappaB p65 serine 536 phosphorylation induced by $\mathrm{T}$ cell costimulation is mediated by I kappaB kinase beta and controls the kinetics of p65 nuclear import. J Immunol 172: 6336-6344, 2004.

8. Huang H, Lin H, Zhang X and Li J: Resveratrol reverses temozolomide resistance by downregulation of MGMT in T98G glioblastoma cells by the NF- $\kappa \mathrm{B}-$ dependent pathway. Oncol Rep 27: 2050-2056, 2012.

9. Gupta SC, Patchva S, Koh W and Aggarwal BB: Discovery of curcumin, a component of golden spice and its miraculous biological activities. Clin Exp Pharmacol Physiol 39: 283-299, 2012.

10. Shakibaei M, Mobasheri A, Lueders C, Busch F, Shayan P and Goel A: Curcumin enhances the effect of chemotherapy against colorectal cancer cells by inhibition of NF- $\kappa \mathrm{B}$ and Src protein kinase signaling pathways. PLoS One 8: e57218, 2013.

11. Orr WS, Denbo JW, Saab KR, et al: Curcumin potentiates rhabdomyosarcoma radiosensitivity by suppressing NF- $\kappa \mathrm{B}$ activity. PLoS One 8: e51309, 2013.

12. Dhandapani KM, Mahesh VB and Brann DW: Curcumin suppresses growth and chemoresistance of human glioblastoma cells via AP-1 and NFkappaB transcription factors. J Neurochem 102: 522-538, 2007.

13. Ramachandran C, Nair SM, Escalon E and Melnick SJ: Potentiation of etoposide and temozolomide cytotoxicity by curcumin and turmeric force in brain tumor cell lines. J Complement Integr Med 9: Article 20, 2012.
14. Fabbri M: MicroRNAs and cancer: towards a personalized medicine. Curr Mol Med 13: 751-756, 2013.

15. Williams AE: Functional aspects of animal microRNAs. Cell Mol Life Sci 65: 545-562, 2008.

16. Sha M, Ye J, Zhang LX, Luan ZY and Chen YB: Celastrol induces apoptosis of gastric cancer cells by miR-146a inhibition of NF- $\kappa$ B activity. Cancer Cell Int 13: 50, 2013.

17. Crone SG, Jacobsen A, Federspiel B, Bardram L, Krogh A, Lund AH and Friis-Hansen L: microRNA-146a inhibits G protein-coupled receptor-mediated activation of $\mathrm{NF}-\kappa \mathrm{B}$ by targeting CARD10 and COPS8 in gastric cancer. Mol Cancer 11: 71,2012.

18. Bao B, Ali S, Banerjee S, et al: Curcumin analogue CDF inhibits pancreatic tumor growth by switching on suppressor microRNAs and attenuating EZH2 expression. Cancer Res 72: 335-345, 2012.

19. Park MH, Ahn BH, Hong YK and Min do S: Overexpression of phospholipase D enhances matrix metalloproteinase-2 expression and glioma cell invasion via protein kinase $\mathrm{C}$ and protein kinase A/NF-kappaB/Sp1-mediated signaling pathways. Carcinogenesis 30: 356-365, 2009.

20. Livak KJ and Schmittgen TD: Analysis of relative gene expression data using real-time quantitative PCR and the $2-\Delta \Delta \mathrm{Ct}$ method. Methods 25: 402-408, 2001.

21. Agrawal DK and Mishra PK: Curcumin and its analogues: potential anticancer agents. Med Res Rev 30: 818-860, 2010.

22. Goel A and Aggarwal BB: Curcumin, the golden spice from Indian saffron, is a chemosensitizer and radiosensitizer for tumors and chemoprotector and radioprotector for normal organs. Nutr Cancer 62: 919-930, 2010.

23. Chainani-Wu N: Safety and anti-inflammatory activity of curcumin: a component of tumeric (Curcuma longa). J Altern Complement Med 9: 161-168, 2003.

24. Zanotto-Filho A, Braganhol E, Edelweiss MI, et al: The curry spice curcumin selectively inhibits cancer cells growth in vitro and in preclinical model of glioblastoma. J Nutr Biochem 23: 591-601, 2012.

25. Aoki H, Takada Y, Kondo S, Sawaya R, Aggarwal BB and Kondo Y: Evidence that curcumin suppresses the growth of malignant gliomas in vitro and in vivo through induction of autophagy: role of Akt and extracellular signal-regulated kinase signaling pathways. Mol Pharmacol 72: 29-39, 2007.

26. Koshkin PA, Chistiakov DA and Chekhonin VP: Role of microRNAs in mechanisms of glioblastoma resistance to radioand chemotherapy. Biochemistry (Mosc) 78: 325-334, 2013.

27. Wong ST, Zhang XQ, Zhuang JT, Chan HL, Li CH and Leung GK: MicroRNA-21 inhibition enhances in vitro chemosensitivity of temozolomide-resistant glioblastoma cells. Anticancer Res 32: 2835-2841, 2012.

28. Ujifuku K, Mitsutake N, Takakura S, et al: miR-195, miR-455-3p and miR-10a $(*)$ are implicated in acquired temozolomide resistance in glioblastoma multiforme cells. Cancer Lett 296: 241-248, 2010.

29. Mei J, Bachoo R and Zhang CL: MicroRNA-146a inhibits glioma development by targeting Notch1. Mol Cell Biol 31: 3584-3592, 2011.

30. Pogribny IP, Filkowski JN, Tryndyak VP, Golubov A, Shpyleva SI and Kovalchuk O: Alterations of microRNAs and their targets are associated with acquired resistance of MCF-7 breast cancer cells to cisplatin. Int J Cancer 127: 1785-1794, 2010.

31. Atkinson GP, Nozell SE and Benveniste ET: NF-kappaB and STAT3 signaling in glioma: targets for future therapies. Expert Rev Neurother 10: 575-586, 2010.

32. Fukushima T, Kawaguchi M, Yorita K, et al: Antitumor effect of dehydroxymethylepoxyquinomicin, a small molecule inhibitor of nuclear factor- $\kappa B$, on glioblastoma. Neuro Oncol 14: 19-28, 2012.

33. Brassesco MS, Roberto GM, Morales AG, et al: Inhibition of NF- $\kappa$ B by dehydroxymethylepoxyquinomicin suppresses invasion and synergistically potentiates temozolomide and $\gamma$-radiation cytotoxicity in glioblastoma cells. Chemother Res Pract 2013: 593020, 2013.

34. Paik JH, Jang JY, Jeon YK, et al: MicroRNA-146a downregulates NFKB activity via targeting TRAF6 and functions as a tumor suppressor having strong prognostic implications in NK/T cell lymphoma. Clin Cancer Res 17: 4761-4771, 2011. 